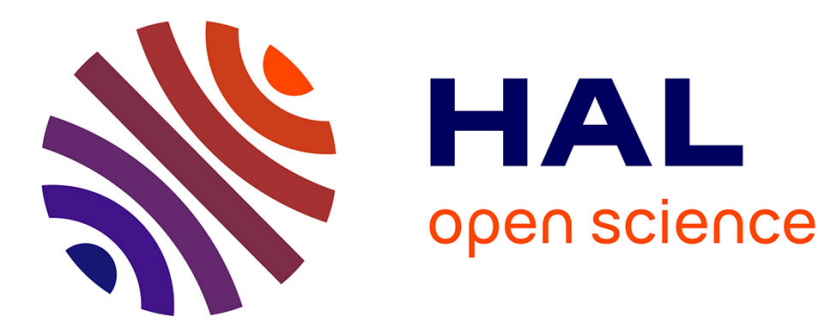

\title{
Physiological heart activation by adrenaline involves parallel activation of ATP usage and supply
}

Bernard Korzeniewski, Véronique Deschodt-Arsac, Guillaume Calmettes, Jean-Michel Franconi, Philippe H Diolez

\section{To cite this version:}

Bernard Korzeniewski, Véronique Deschodt-Arsac, Guillaume Calmettes, Jean-Michel Franconi, Philippe H Diolez. Physiological heart activation by adrenaline involves parallel activation of ATP usage and supply. Biochemical Journal, 2008, 413 (2), pp.343-347. 10.1042/BJ20080162 . hal00478958

\section{HAL Id: hal-00478958 \\ https://hal.science/hal-00478958}

Submitted on 30 Apr 2010

HAL is a multi-disciplinary open access archive for the deposit and dissemination of scientific research documents, whether they are published or not. The documents may come from teaching and research institutions in France or abroad, or from public or private research centers.
L'archive ouverte pluridisciplinaire HAL, est destinée au dépôt et à la diffusion de documents scientifiques de niveau recherche, publiés ou non, émanant des établissements d'enseignement et de recherche français ou étrangers, des laboratoires publics ou privés. 


\title{
Physiological heart activation by adrenaline involves parallel activation of ATP usage and supply
}

\author{
Bernard Korzeniewski ${ }^{1,2}$, Véronique Deschodt-Arsac ${ }^{1}$, Guillaume Calmettes ${ }^{1}$, Jean-Michei \\ Franconi $^{1}$, and Philippe Diolez ${ }^{1}$
}

${ }^{1}$ Résonance Magnétique des Systèmes Biologiques, UMR5536 Centre National de la Recherche Scientifique - Université Victor Segalen Bordeaux 2, France.

${ }^{2}$ Faculty of Biochemistry, Biophysics and Biotechnology, Jagiellonian University, Kraków, Poland.

Correspondence: Philippe Diolez, Résonance Magnétique des Systèms Biologiques, UMR5536 CNRS - Université Victor Segalen Bordeaux 2, 146 rue Léo-Saignat, 33076 Bordeaux cedex, France, e-mail:

Diolez@rmsb.u-bordeaux2.fr

Short title: Adrenaline-induced parallel activation of ATP usage and demand in heart 


\section{SYNOPSIS}

During low-to-high work transition in adult mammalian heart in vivo the concentrations of free ADP, ATP, $\mathrm{PCr}$ (phosphocreatine), $\mathrm{P}_{\mathrm{i}}$ and $\mathrm{NADH}$ are essentially constant, in striking contrast with skeletal muscle. The direct activation by calcium ions of ATP usage and feedback activation of ATP production by ADP (and $\mathrm{P}_{\mathrm{i}}$ ) alone cannot explain this perfect homeostasis. A comparison of the response to adrenaline (increase in rate-pressure product and $[\mathrm{PCr}]$ ) of the intact beating perfused rat heart with the elasticities of the $\mathrm{PCr}$ producer and consumer to $\mathrm{PCr}$ concentration demonstrated that both the ATP/PCr-producing block and ATP/PCr-consuming block are directly activated to a similar extent during physiological heart activation. Our finding constitutes a direct evidence for the parallelactivation mechanism of the regulation of oxidative phosphorylation in heart postulated previously in the theoretical way.

Keywords: oxidative phosphorylation, regulation of metabolism, mammalian heart, work transitions, catecholamines, Proportional Activation Approach 


\section{INTRODUCTION}

During transition from low to high work intensity induced by increased pacing frequency or hormones (catecholamines) the demand for ATP and rate-pressure product (RPP) in mammalian heart can increase 3-5 times [1-3]. The main source of ATP in heart under normal conditions is oxidative phosphorylation. Therefore, the rate of oxidative ATP production must be elevated in order to avoid a quick ATP exhaustion, and indeed such an increase in the respiration rate $\left(\mathrm{VO}_{2}\right)$ was observed $[1,3]$. However, the mechanism responsible for the adjusting of the rate of ATP production to the current energy demand still remains a matter of debate.

The negative feedback through ADP (and $\mathrm{P}_{\mathrm{i}}$ ) [4] and the activation of NADH supply (TCA cycle dehydrogenases) by calcium ions observed in vitro [5,6] cannot be the mechanism looked for, because in intact heart the concentrations of free ADP, $P_{i}$ and $N A D H$ are essentially stable [1-3,7]. It has been postulated that $\mathrm{Ca}^{2+}$ ions activate ATP synthase in isolated mitochondria [8,9], but the quantitative relevance of this effect under in vivo conditions is not known. It has been shown, using Proportional Activation Approach (PAA), that vasopressin activates to a similar extent the $\Delta \Psi$ (mitochondrial membrane potential)-producing and $\Delta \Psi$-consuming system in isolated hepatocytes [10]. It was also proposed, on the basis of theoretical studies using the computer model of oxidative phosphorylation developed by Korzeniewski and co-workers, that most or all oxidative phosphorylation complexes (complex I, complex III, complex IV, ATP synthase, ATP/ADP carrier, $\mathrm{P}_{\mathrm{i}}$ carrier) are directly activated in skeletal muscle, heart and other tissues during elevated energy demand [11-13]. The evidences supporting this parallel-activation or each-step-activation mechanism are summarized in a recent paper [14]. A similar idea, called 'multi-site modulation', was developed in a more abstract and general way by Fell and Thomas [15].

Finally, it was demonstrated recently [16], using Modular Control Analysis (MoCA) [16-18], that an elevated calcium ion concentration in perfusate activates both ATP/PCr-consuming and ATP/PCr producing metabolic block in perfused rat heart. However, while these conditions effectively change cytosolic calcium concentrations [19,20], it appeared crucial to evidence this parallel activation in the ATP supply - ATP usage system under more physiological conditions of heart stimulation.

In the present paper Proportional Activation Approach (PAA) is used to determine quantitatively the direct activation of the ATP/PCr-producing block and ATP/PCr-consuming block during activation of perfused rat heart by adrenaline, a physiological heart stimulator. Changes in the flux (rate-pressure product, RPP) and [PCr] were measured in order to determine the elasticity of the two blocks to $\mathrm{PCr}$, and the response of the system to adrenaline. The elasticity of the consumer was determined by an addition of an inhibitor of the producer $(\mathrm{NaCN})$, while the elasticity of the producer was determined either by activation (increase in the balloon volume in the left ventricle) or inhibition (addition of BDM - inhibitor of actomyosine-ATPase) of the consumer. Adrenaline administration caused an increase in RPP and, surprisingly, a slight increase in [PCr]. These results constitute a direct evidence for the parallel activation of the ATP/PCr production and ATP/PCr consumption in perfused rat heart stimulated by adrenaline. 


\section{METHODS}

\section{Experimental Procedures}

Langendorf perfusion and NMR measurements procedures for perfused rat (Male SpragueDawley rats : 350-400g) heart were described previously [16]. Hearts were perfused by an aortic canula at constant pressure $(100 \mathrm{~mm} \mathrm{Hg})$ with Krebs-Henseleit solution $(95 \% \mathrm{O} 2$ and $5 \% \mathrm{CO} 2, \mathrm{pH}$ 7.35 , temperature $37^{\circ} \mathrm{C}$ ) containing $10 \mathrm{mmol} / \mathrm{L} \mathrm{Na-pyruvate}$ as substrate and actual free calcium concentration set to $2.0 \mathrm{mmol} / \mathrm{L}$. Left ventricle systolic pressure (LVP) of unpaced heart was measured under isovolumic conditions of contraction thanks to a latex balloon inserted into the left ventricle and connected to a pressure transducer. Mechanical performance was evaluated as the product of heart frequency and developed pressure (RPP, in $\mathrm{mmHg}$.beat. $\mathrm{min}^{-1}$ ). Perfused heart was placed into a $20 \mathrm{~mm}$ NMR tube inserted into a 9.4-T super-conducting magnet equipped with a 20-mm bore (Bruker DPX400 Avance) for 31P NMR spectroscopy. In order to eliminate endogenous substrates and remaining anesthetics, at least 20 minutes were allowed for stabilization of heart activity before any measurement was made.

For the study of steady state modifications four NMR spectra $(5 \mathrm{~min}$ duration time for each spectrum) were acquired before modulation was applied, then after a transition time equivalent to one spectrum (5 min) four new spectra (20 min) were recorded. Each steady state (before and after modulation) was characterized by the mean values of the four spectra for phosphorylated compounds and the corresponding four RPP values. Modulations of steady state were carried out using a lateral infusion of concentrated Butanedione monoxime (BDM) solution to a final concentration of $10 \mathrm{mM}$ and $\mathrm{NaCN}$ to a final concentration of $0.3 \mathrm{mM}$. Data on the increase in balloon volume were taken from previous experiments [16]. The effect of two adrenaline concentrations ( 0.8 and $1.6 \mu \mathrm{g} / \mathrm{L})$ was studied (see Fig. 1 for an example).

\section{Statistical analysis}

Experimental values are reported as means \pm standard deviation (SD) for $\mathrm{n}$ independent rat hearts. Statistical comparisons between the slopes of the two adrenaline treated groups versus balloon group were performed by analysis of variance (ANOVA). Experimental values of $\triangle \mathrm{PCr} / \mathrm{PCr}$ and $\triangle R P P / R P P$ were simulated from observed means and standard deviations by using Monte Carlo simulations [21]. Simulations were based on a normal distribution with a mean equal to the mean of the experimental points and an SD equal to the SD of the experimental points.

\section{Theoretical Methods}

In our present analysis the bioenergetic system in heart was conceptually divided into two blocks (or modules): PCr production and PCr consumption. PCr was chosen as the representative of the group of metabolites ( $\mathrm{PCr}, \mathrm{Cr}, \mathrm{ATP}, \mathrm{ADP}, \mathrm{P}_{\mathrm{i}}$ ) characterized by a unique relationship between their concentrations [16]. The distinguished blocks 'communicate' with each other only via these metabolites.

The Proportional Activation Approach (PAA) [10] was used in the present work to analyze, interpret and visualize the experimental data. PAA defines the proportional activation coefficient as the 
ratio of the relative direct activation by some factor $F$ (for instance adrenaline) of the consumer $(C)$ of some metabolite $\mathrm{M}$ (for instance $\mathrm{PCr}$ or ATP) to the relative direct activation of the producer $(\mathrm{P})$ : $(\Delta C / C) /(\Delta P / P)[10]$. It was shown [10] that this coefficient equals:

$$
P_{F}^{P C}=\frac{1-\varepsilon_{M}^{C} \cdot \tau}{1-\varepsilon_{M}^{P} \cdot \tau}
$$

where $\varepsilon_{M}^{C}=(\Delta C / C) /(\Delta M / M)$ and $\varepsilon_{M}^{P}=(\Delta P / P) /(\Delta M / M)$ are elasticities of the consumer and producer to $M$, respectively, while $\tau$ is the response of the system to the factor $F$, defined as the relative change in the metabolite concentration divided by the relative change in flux: $(\Delta M / M) /(\Delta J / J)$. Due to PAA when $\tau=0$ (no changes in M; horizontal line in Fig. 2), both $P$ and $C$ are directly activated to the same extent $\left(P_{F}^{P C}=1\right)$; when $\tau$ equals $1 / \varepsilon_{M}^{C}$ (the relevant curves overlap) only $\mathrm{P}$ is activated; when $\tau$ equals $1 / \varepsilon_{M}^{P}$ (the relevant curves overlap) only $\mathrm{C}$ is activated; and in the intermediate cases both $\mathrm{C}$ and $\mathrm{P}$ are activated to the relative extent characterized by $P_{F}^{P C}$

In the present work PAA was used to determine quantitatively the respective direct activation of the ATP/PCr-producing and ATP/PCr-consuming blocks during activation of perfused rat heart by adrenaline, a physiological heart stimulator. Changes in the flux (rate-pressure product) and [PCr] were measured in order to determine the kinetic response (elasticity) of the two blocks to PCr, and the overall response of the system to adrenaline. The elasticity of the consumer was determined by addition of an inhibitor of the producer ( $\mathrm{NaCN})$ [16], while the elasticity of the producer was determined either by activation (increase in the balloon volume in the left ventricule, Frank-Starling effect) [16] or by inhibition (addition of BDM - inhibitor of actomyosin-ATPase [22]) of the consumer. 


\section{RESULTS AND DISCUSSION}

In the reference point (no NaCN, BDM or adrenaline added, standard balloon volume) the average RPP was equal to 24389 ( \pm 5633 ) in $\mathrm{mmHg}$.beat. $\mathrm{min}^{-1}$ and the average $[\mathrm{PCr}$ ] was equal to $17.63( \pm 1.34) \mathrm{mM}$. The elasticities of the producer and consumer blocks, as well as the effect of adrenaline were determined around this point.

Adrenaline increased the flux (rate-pressure product) by 73 or $84 \%$ at the concentration of 0.8 and $1.6 \mu \mathrm{g} / \mathrm{L}$, respectively. At the same time, $\mathrm{PCr}$ concentration was approximately constant (slight increase) at the lower adrenaline concentration (Fig. 1), or even increased $(+4 \%)$ above the reference point value at the higher concentration. All results are presented in Fig. 2 - drawn in the convention of PAA [10] - where percentage changes in RPP and [PCr] are shown in order to compare different experiments and to present relative changes necessary for the quantitative analysis. The lines representing the elasticities of the $\mathrm{PCr}$ producer and consumer to $[\mathrm{PCr}]$ are also presented. The (absolute value of the) elasticity of the consumer obtained by $\mathrm{NaCN}$ addition (equal to 0.57 ) is significantly smaller than the elasticity of the producer obtained by two independent experimental methods: an increase in the balloon volume (-11.2) or by an addition of BDM (-8.2), of which the first activates and the second inhibits the consumer. Additionally, these two measured producer elasticity values were not significantly different, and the mean value of -9.7 was taken for the quantitative analysis.

The line corresponding to the activation of heart contraction by adrenaline lies between the lines representing the elasticities and is nearly horizontal and even slightly bent upward, especially at the higher adrenaline concentration. The calculated proportional activation coefficients for the two adrenaline concentrations are: 0.76 (for $0.8 \mu \mathrm{g} / \mathrm{L}$ ) 0.65 (for $1.6 \mu \mathrm{g} / \mathrm{L}$ ). Statistical analysis demonstrated that the adrenaline slopes are both highly significantly different from the balloon slope: $p<0.001$, and also evidently from the $\mathrm{NaCN}$ slope. The experimental data presented clearly show that, in perfused beating rat heart, adrenaline directly activates both the ATP/PCr-producing and ATP/PCr-consuming metabolic blocks in rat perfused heart. Effectively, if only the consumer were directly activated and the producer were activated only indirectly - through changes in $[A D P]$ and/or $\left[\mathrm{P}_{i}\right]$ - the response-toadrenaline line would overlap with the elasticity-of-producer line. Moreover, at both adrenaline concentrations the producer appears to be even more activated than the consumer, since [PCr] even rises above the reference point (no adrenaline) and thus the proportional activation coefficient is lower than 1 (a value of 1 corresponding to an equal activation of both modules).

The elasticity of the consumer (obtained by $\mathrm{NaCN}$ addition) is low, much lower than $1 / \tau$, and therefore, according to Eq. 1, has a relatively low impact on the value of the proportional activation coefficient. Much more important is the elasticity of the producer, because its value is relatively high (closer to $1 / \tau$ ) and therefore the lines corresponding to the elasticity of the producer $\varepsilon^{P}$ and adrenaline response $1 / t$ lie near each other in Fig. 2. For this reason this latter elasticity was measured using two independent methods: the similarity of the values obtained in both ways strongly enhances the reliability of the elasticity determination. 
The increase in the balloon volume in the left ventricle is intended to change [PCr] without direct disturbance of $\mathrm{PCr}$ producer by increasing myofibril ATPase sensitivity to calcium (FrankStarling effect), and thus to measure the $\mathrm{PCr}$ producer response to $[\mathrm{PCr}]$. The effect of the increased balloon volume, modelling an increase in afterload blood pressure, may be complex since the shape of the internal surface of the ventricle is not perfectly ellipsoid (as the shape of the balloon) and therefore ventricular cells may be affected to different extents. However, both RPP and NMR signals come from (are averaged over) the entire heart and therefore the effect of the discussed heterogeneity on our results should not be significant. This expectation is supported by the very similar values of the elasticity of $\mathrm{PCr}$ producer to $\mathrm{PCr}$ obtained using the balloon volume increase and BDM administration encountered in the present study.

It has been assumed in the present study that the increase in the balloon volume/BDM addition activates/inhibits directly only the PCr consumer, but not producer. It has been shown previously that the rapid increase in twich force after muscle stretch was not associated with a rise in the calcium transient $[23,24]$ or a modification of calcium circulation [25]. It has been found in two studies that BDM does not affect significantly the calcium transient [22,26] (BDM was used in those studies as actomyosin-ATPase inhibitor that does not affect the calcium level), while in another study a significant increase in calcium transient was encountered [27]. However, the fact that the measured elasticity of $\mathrm{PCr}$ producer to $[\mathrm{PCr}]$ is similar regardless it is determined by the balloon volume increase or by BDM addition suggests that in our system BDM does not affect significantly the PCr producer. Furthermore, the slopes of the response to the balloon volume increase and to adrenaline addition are significantly different, as discussed above. These results indicate that, even if (for some reason) the increase in the balloon volume and/or BDM directly affects the PCr producer, adrenaline activates $\mathrm{PCr}$ producer much more, what would even strengthen our conclusions concerning the parallel activation of ATP supply and demand. The 'small' changes in [PCr] present in the response of $\mathrm{PCr}$ producer to $[\mathrm{PCr}]$ do not exclude e.g. the regulation of oxidative phosphorylation by [ADP] [4]. One must bear in mind that at high $\mathrm{PCr} / \mathrm{Cr}$ ratio present in heart perfused with pyruvate, a small relative change in $[\mathrm{PCr}]$ may be associated with a great relative change in [Cr], in the $\mathrm{PCr} / \mathrm{Cr}$ ratio and, consequently, in [ADP]. For instance, if the $\mathrm{PCr} / \mathrm{Cr}$ ratio equals 10 , a decrease in $[\mathrm{PCr}$ by only $10 \%$ is equivalent to a 2.2 -fold (by $120 \%$ ) decrease in the $\mathrm{PCr} / \mathrm{Cr}$ ratio and a similar relative increase in [ADP] ([ATP] remains essentially constant because of the very high ATP/ADP ratio). It is worth to notice that the elasticity of the PCr producer to [PCr] measured by an increase of the balloon volume is much (2.5 times) smaller in heart perfused with glucose, where significantly smaller $\mathrm{PCr}$ concentration than in heart perfused with pyruvate was measured [16]. The calculated $\mathrm{PCr} / \mathrm{Cr}$ ratio (and ADP concentration) depends extremely on the assumed total creatine pool concentration. If the value of $20 \mathrm{mM}$ is assumed for ref. 16, the calculated $\mathrm{PCr} / \mathrm{Cr}$ ratio is about 10 for pyruvate and about 2 for glucose.

It has been proposed that the relative stability of ADP during work transitions in heart is related to the fact that inorganic phosphate, and not ADP, is the main regulatory metabolite of oxidative phosphorylation [28]. However, this explanation works only for very unphysiological assumptions: that $\left[\mathrm{P}_{\mathrm{i}}\right]$ is in the micromollar range at low heart work and increases by about three orders of magnitude during transition to high work, and that the proton leak is responsible for (almost) all oxygen consumption at low work (virtually no ATP production by oxidative phosphorylation) (see 
[14] for extensive discussion). The present study delivers subsequent evidences that the discussed proposal is incorrect. First, the NMR signal from $P_{i}$ could be seen at low work intensities (see Fig. 1), proving that $\left[\mathrm{P}_{\mathrm{i}}\right]$ is in the millimolar range, and does not change much during heart activation [16]. The effect of adrenaline measured here clearly does not overlap with the elasticity of the producer, what should be expected if oxidative phosphorylation is regulated exclusively by the concentration of metabolites (PCr, Cr, ADP, $\mathrm{P}_{\mathrm{i}}$, ATP, AMP). Furthermore, the potential activation of oxidative phosphorylation by $\mathrm{P}_{\mathrm{i}}$ cannot explain the adrenaline-induced increase in $[\mathrm{PCr}]$, nor the stability of NADH observed by other authors [3,7].

A great advantage of Parallel Activation Approach is that it does not rely on any particular mechanism of the regulation of oxidative phosphorylation (or - more generally - of PCr producer) by intermediate metabolite concentrations. It is valid for various potential mechanisms: hyperbolic dependence of oxidative ATP production on ADP concentration [4], ultrasensitivity to ADP concentration [29], regulation by $\mathrm{P}_{\mathrm{i}}$ concentration [28] or the 'phosphocreatine circuit' associated with metabolite compartmentalization [30]. Whatever the mechanism, it remains the same for the response of the $\mathrm{PCr}$ producer to $[\mathrm{PCr}]$ and for adrenaline administration. The statistically significant difference between the adrenaline slope and producer slope means that the producer was directly activated by adrenaline more than by the increase in the balloon volume. Even if the balloon and BDM affect directly not only the consumer, but also the producer, adrenaline stimulates directly the producer even more, in accordance with the parallel activation mechanism. The only condition of the validity of the method is that there exists a unique relationship between different energy metabolite concentrations in different compartments for the producer response and for adrenaline addition.

The results obtained in the present study constitute clear and significant advance in relation to our previous experimental studies demonstrating parallel activation in the energetic system of the cell $[10,16]$. In ref. 10 vasopressin-induced parallel activation of $\Delta \Psi$-producing and $\Delta \Psi$-consuming block was evidenced in a not quite physiological system of cells isolated from non-excitable tissue: hepatocytes. In ref. 16 increase in perfusate calcium ion concentration was used to trigger heart stimulation since cytoplasmic calcium is porportional to perfusate concentration [20]. This mechanism - cytoplasmic calcium concentration increase - caused a much smaller increase in RPP than adrenaline administration and no change in [PCr]. Finally, in the present study the value of the elasticity of the PCr producer to PCr obtained using the increase in the balloon volume was confirmed independently using BDM administration.

Of course the present work can and should be continued and extended in even more physiological conditions, especially in paced heart in situ, where excellent stability of energy metabolites was observed previously [1,2].

The exact nature of the cytosolic factor/mechanism that directly activates ATP production in response to stimulation by adrenaline remains unknown but probably involves calcium ions. It was proposed previously [14] that this factor/mechanism may be the frequency of calcium ion oscillations that is integrated over time by, for instance, protein phosphorylation/dephosphorylation. While TCA cycle dehydrogenases would need matrix $\mathrm{Ca}^{2+}$ for the activation, the transmembrane oxidative phosphorylation complexes (complex I, complex III, complex IV, ATP synthase, ATP/ADP carrier, phosphate carrier) may be equally well activated by cytosolic calcium. The parallel activation of the 
ATP producer and consumer in mammalian heart physiologically stimulated by adrenaline, documented experimentally in the present work, was previously predicted by computer modelling of oxidative phosphorylation $[12,13,31]$. Therefore the present study represents a demonstration of the possibility to predict the existence of new, still undiscovered phenomena in biology. 


\section{REFERENCES}

1. Katz L.A., Swain, J.A., Portman, M.A. and Balaban, R.S. (1989) Relation between phosphate metabolites and oxygen consumption of heart in vivo. Am. J. Physiol. 256, H265-H274

2. Balaban, R.S., Kantor, H.L., Katz, L.A. and Briggs, R.W. (1986) Relation between work and phosphate metabolite in the in vivo paced mammalian heart. Science 232, 1121-1123

3. Sharma, N., Okere, I.C., Brunengraber, D.Z., McElfresh, T.A., King, K.L., Sterk, J.P., Huang, H., Chandler, M.P. and Stanley, W.C. (2005) Regulation of pyruvate dehydrogenase activity and citric acid cycle intermediates during high cardiac power generation. J. Physiol. 562, 593-603

4. Chance, B. and Williams, G.R. (1955) Respiratory enzymes in oxidative phosphorylation. I. Kinetics of oxygen utilization. J. Biol. Chem. 217, 383-393

5. McCormack, J.G., Halestrap, A.P. and Denton, R.M. (1990) Role of calcium ions in regulation of mammalian intramitochondrial metabolism. Physiol. Rev. 70, 391-425

6. Hansford, R.G. Control of mitochondrial substrate oxidation. (1980) Curr. Top. Bioenerg. 10, $217-$ 277

7. Heineman, F.W. and Balaban, R.S. (1993) Effects of afterload and heart rate on NAD(P)H redox state in the isolated rabbit heart. Am. J. Physiol. 264, H433-H440

8. Territo, P.R., Mootha, V.K., French, S.A. and Balaban, R.S. (2000) $\mathrm{Ca}^{2+}$ activation of heart

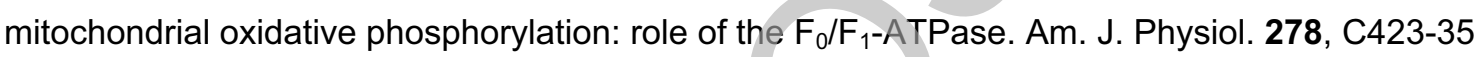

9. Baniene, R. and Mildaziene, V. (2005) Stimulation of ATP synthase by $\mathrm{Ca}^{2+}$ in heart mitochondria.

Biologija 1, 20-23

10. Korzeniewski, B., Harper, M.-E. and Brand, M.D. (1995) Proportional activation coefficients during stimulation of oxidative phosphorylation by lactate and pyruvate or by vasopressin. Biochim. Biophys. Acta 1229, 315-322

11. Korzeniewski, B. (1998) Regulation of ATP supply during muscle contraction: theoretical studies.

Biochem. J. 330, 1189-1195

12. Korzeniewski, B., Noma, A. and Matsuoka, S. ( 2005) Regulation of oxidative phosphorylation in intact mammalian heart in vivo. Biophys. Chem. 116, 145-157

13. Korzeniewski, B. (2006) Oxygen consumption and metabolite concentrations during transitions between different work intensities in heart. Am. J. Physiol. 291, 1466-1471

14. Korzeniewski, B. (2007) Regulation of oxidative phosphorylation through parallel activation. Biophys. Chem. 129, 93-110

15. Fell, D.A. and Thomas S. (1995) Physiological control of metabolic flux: the requirement for multisite modulation. Biochem J 311, 35-39

16. Diolez, P., Descholdt-Arsac, V., Raffard, G., Simon, C., Dos Santos, P., Thiaudiere, E., Arsac, L. and Franconi, J.-M. (2007) Modular regulation analysis of heart contraction: application to in situ demonstration of a direct mitochondrial activation by calcium in beating heart. Am. J. Physiol. 293, R13-R19

17. Diolez, P., Raffard, G., Simon, C., Leducq, N., Dos Santos, P. and Canioni, P. (2002) Mitochondria do not control heart bioenergetics. Molecular Biology Reports 29, 193-196 
18. Brand, M.D. and Curtis RK. (2002) Simplifying metabolic complexity. Biochem Soc Trans 30, 2530

19. Wu, S.T., Kojima, S., Parmley, W.W. and Wikman-Coffelt, J. (1992) Relationship between cytosolic calcium and oxygen consumption in isolated rat hearts. Cell Calcium 13, 235-247

20. Balaban, R. Cardiac energy metabolism homeostasis: role of cytosolic calcium. (2002) J Mol Cell Cardiol 34, 1259-1271

21. Ainscow, E.K. and Brand, M.D. (1998) Errors associated with metabolic control analysis. Application of Monte-Carlo simulation of experimental data. J. Theor. Biol. 194, 223-233

22. Doumen, C., Wan, B. and Ondrejickova, O. (1995) Effect of BDM, verapamil, and cardiac work on mitochondrial membrane potential in perfused rat hearts. Am. J. Physiol. 269, H515-23

23. Kentish, J.C., Wrzosek, K. (1998) Changes in force and cytosolic $\mathrm{Ca}^{2+}$ concentration after length changes in isolated rat ventricular trabeculae. J. Physiol. 506, 431-444.

24. Macgowan, G.A., Kirk, J.A., Evans, C. and Shroff, S.G. (2006) Pressure-calcium relationships in the perfused mouse heart. Am. J. Physiol. 290, H2614-H2624.

25. Mizumo, J., Araki, J., Mohri, S., Minami, H., Doi, Y., Fujinaka, W., Miyaji, K., Kiyooka, T., Oshima, J., Iribe, G., Hirakawa, M. and Suga, H. (2001) Frank-Starling mechanism retains recirculation fraction of myocardial $\mathrm{Ca}^{2+}$ in the beating heart. Jpn. J. Physiol. 51, 733-743.

26. Hitoshi, Y., Slinker, B.K., Mochizuki, T., Lorell, B.H. and LeWinter M.M. (1993) Use of 2,3butanedione monoxime to estimate nonmechanical $\mathrm{VO}_{2}$ in rabbit hearts. Am. J. Physiol. 265, H834$\mathrm{H} 842$.

27. Marijic, J., Buljubasic, N., Stowe, D.F., Turner, L.A., Kampine, J.P. and Bosnjak, Z.J. (1991) Opposing effects of diacetyl monoxime on contractility and calcium transients in isolated myocardium. Am. J. Physiol. 260, H1153-H1159.

28. Beard, D.A. (2006) Modeling of oxygen transport and cellular energetics explains observations on in vivo cardiac energy metabolism. PloS Comp. Biol. 2, 1093-1106

29. Jeneson, J.A., Wiseman, R.W., Westerhoff, H.V. and Kushmerick, M.J. (1996) The signal transduction function of oxidative phosphorylation is at least second order in ADP. J Biol Chem 271, 27995-27998.

30. Walliman, T., Wyss, M., Brdiczka, D. and Nicolay, K. (1992) Intracellular compartmentation, structure and function of creatine kinase isoenzymes in tissues with high and fluctuating energy demands: the 'phosphocreatine circuit' for cellular energy homeostasis. Biochem. J. 281, 21-40. 31. Zhou, L.F., Cabrera, M.E., Okere, I.C., Sharma, N. and Stanley, W.C. (2006) Regulation of myocardial substrate metabolism during increased energy expenditure: insights from computational studies. Am. J. Physiol. 291, H1036 - H1046 
B Biochemical Journal Immediate Publication. Published on 31 Mar 2008 as manuscript BJ20080162

\section{ACKNOWLEDGEMENTS}

This work was supported by the AFM (Association Française contre les Myopathies) and the Région Aquitaine, France. 


\section{FIGURE LEGENDS}

Fig. 1. Typical changes in 31P NMR spectra of perfused rat heart induced by the addition of adrenaline $(0.8 \mu \mathrm{g} / \mathrm{L})$ in the perfusate.

Figure 2: Effect of adrenaline on relative rate-pressure product (RPP) and $[\mathrm{PCr}]$ in perfused rat heart. Two adrenaline concentrations were used: $0.8 \mu \mathrm{g} / \mathrm{L}(\mathrm{n}=4)$ and $1.6 \mu \mathrm{g} / \mathrm{L}(\mathrm{n}=4)$. NaCN administration $(\mathrm{n}=10)$ served determination of $\mathrm{PCr}$ consumer elasticity to $\operatorname{PCr}\left(\varepsilon_{P C r}^{C}\right)$, while BDM administration $(\mathrm{n}=$ 12) and increase in balloon volume in left ventricule $(n=6)$ served determination of PCr producer elasticity to $\operatorname{PCr}\left(\varepsilon_{P C r}^{P}\right)$. Symbols, experimental data; solid lines, experimental effects; dashed lines, linear extrapolations of elasticities. Reference means heart with no interventions; RPP and [PCr] are scaled for $100 \%$ in the reference point. The difference between the adrenaline slopes and balloon slope is statistically significant $(p<0.001)$. 
Figure 1 Control Adrenaline

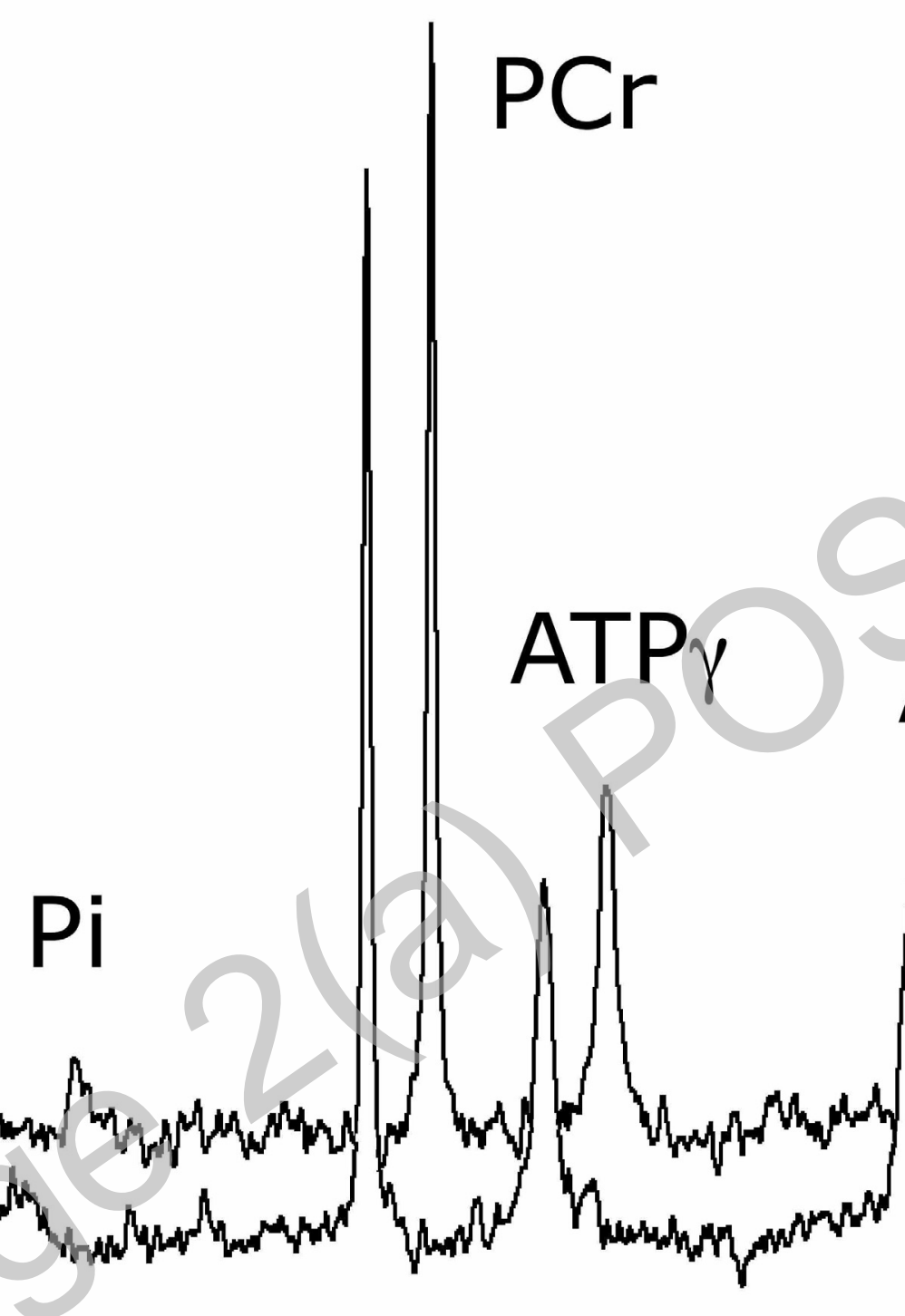

0

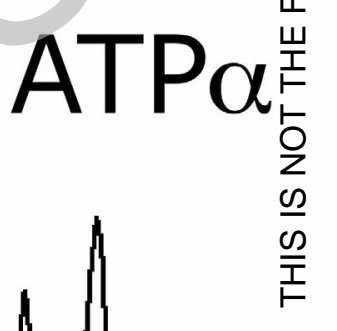

\section{ATP $\beta$}

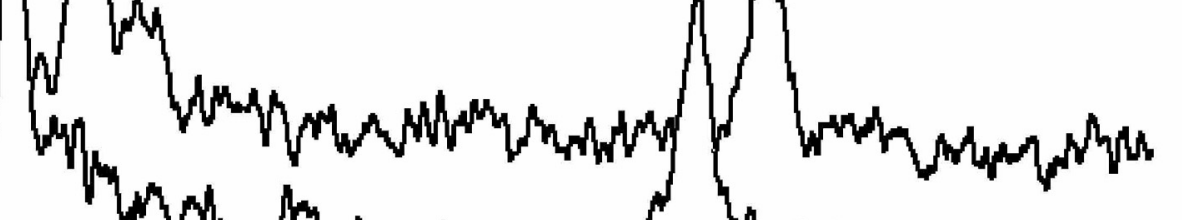

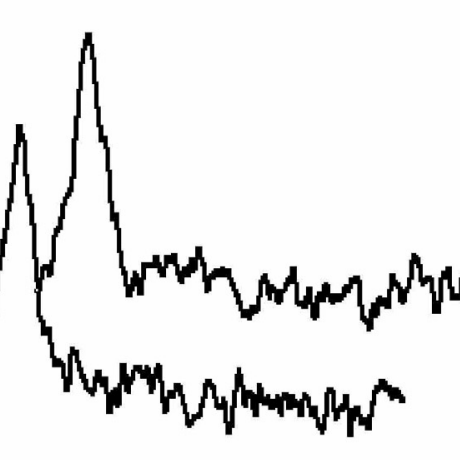

$-10$

$-20$ 


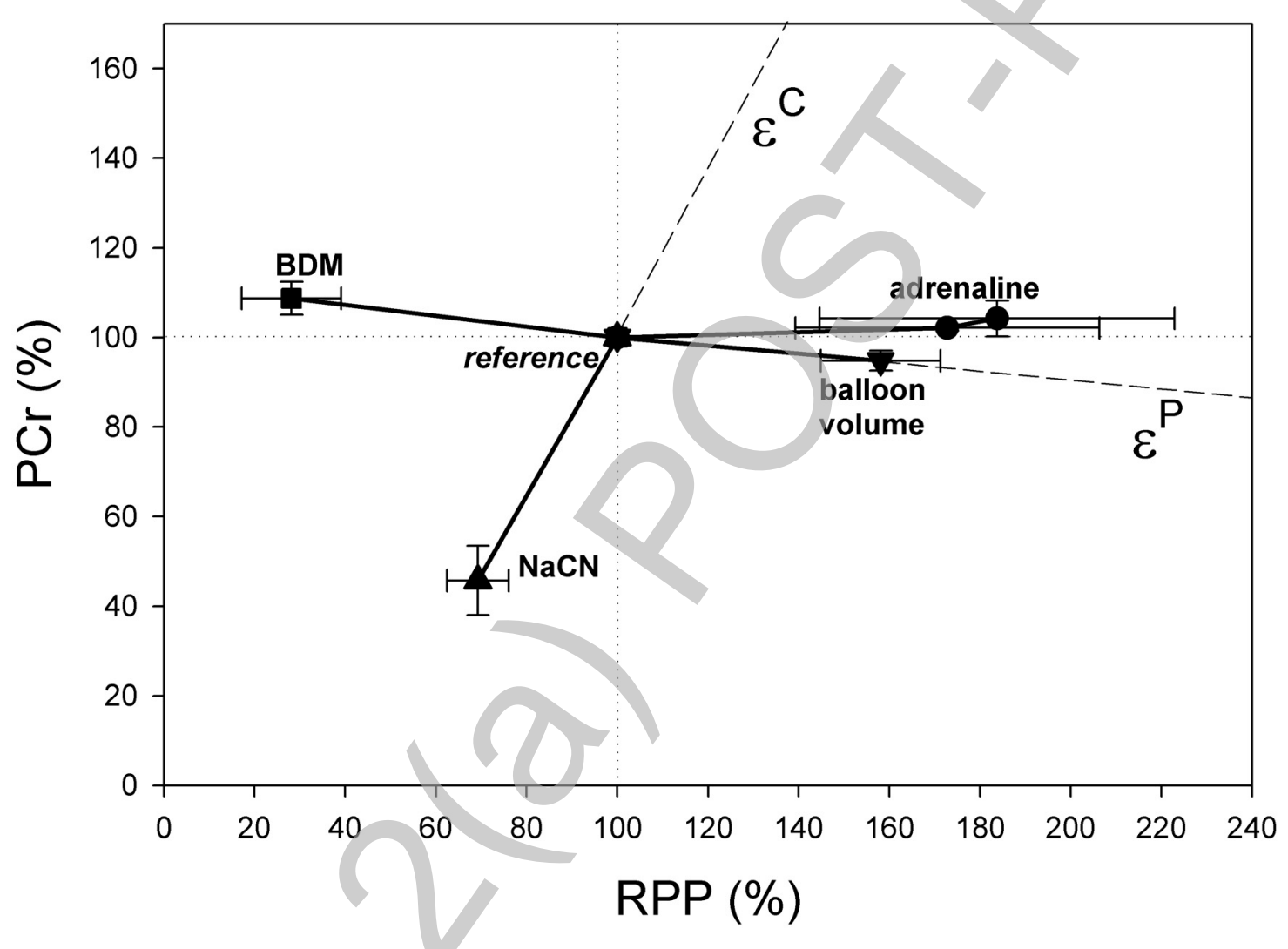

Figure 2 